\title{
Development of Dye Sensitized Solar Cell by Characterizing Polymeric Counter Electrodes
}

\author{
Osama Majeed Butt' ${ }^{1}$, Shazad Maqsood Khan², Muhammad Shakeel Ahmad², \\ Muhammad Umar Manzoor ${ }^{4}$ \\ ${ }^{1}$ Department of Electrical Engineering, University of the Punjab, Pakistan \\ ${ }^{2}$ Department of Polymer Engineering \& Technology, University of the Punjab, Pakistan \\ ${ }^{3}$ UM Power Energy Dedicated Advanced Research Centre, University of Malaya, Malaysia \\ ${ }^{4}$ Department of Metallurgy \& Materials Engineering, University of the Punjab, Pakistan
}

\begin{abstract}
Developments in dye-sensitized solar cells (DSSCs) attracted the attentions of researchers due to their easy fabrication, high efficiency and green energy technique. Recent researches increased their energy conversion technique for their different applications. Conventionally, $\mathrm{Pt}$ or other conductive materials are used as conductive substrate in electrodes and catalysts in dye-sensitized solar cells. The potential advantages of polymer solar cells include high flexibility, good process ability, low material cost and independence from scarce resources. In this work DSSC was fabricated by using glass substrates coated with conductive layer of Indium Tin Oxide (ITO). Graphene, Graphene Oxide and Poly-Aniline were synthesized and used as Photo-cathode (i.e. counter-electrode). Newly fabricated DSSCs were characterized by Scanning Electron Microscope (SEM), Electrochemical Impedance Spectroscopy (EIS) and I-V. Characterizing of DSSCs concluded that graphene showed $2.10 \%$, graphene oxide shows $2.90 \%$ while poly-aniline has $3.96 \%$ efficiency. Though the efficiency of the fabricated cells was found low as compared to conventional Pt made counter electrode but it is much cost effective for insensitive applications at massive scale.
\end{abstract}

Keywords: Solar Energy, DSSC, graphene, poly-aniline, counter electrode, Indium Tin Oxide (ITO)

\section{Introduction}

Solar energy is the most abundant, clean and renewable energy available in the world. Solar radiations are to be counted as 3.8 million EJ/year (Aleklett \& Campbell, 2003). In the last few decades, solar power is considered more important for micro-electro-mechanical system (MEMS) with different kinds of micro or nano size machines(Chen, Chang, \& Zhang, 2012). Researchers are very much interested in fabrication of the thin film solar cells due to their high performance as compared to conventional cell (Malik, Butt, Saad, \& Noor, 2017). Now-a-days, dye-sensitized solar cells (DSSCs) are most popular for research and development in this field. This is due to their simple structure, low fabrication cost and most 
importantly its moderate light-to-electricity conversion efficiency $(10.4 \%)$ (Nazeeruddin et al., 1993; O'regan \& Grfitzeli, 1991). DSSCs are fabricated by combinations of different materials including a transparent electrode coated with a dye sensitized thin mesoporous film of nano-crystalline particles of $\mathrm{TiO} 2$, a counter electrode that is used as a catalyst and an appropriate redox-coupler. An organic dye responsible for producing electricity by converting photons of solar energy in a wide range of light conditions is also used (as shown in figure 1) (Selim \& Mohamed, 2017). Thin mesoporous film of titania and organic dye plays a vital role in the power conversion efficiency of cell (Ahmad, Pandey, \& Rahim, 2017; Hara et al., 2004; Selim \& Mohamed, 2017). Power conversion efficiency varies with dye. For example, the energy conversion efficiency $(\eta)$ of the cells consisting of rosella extract and blue pea extracts alone and mixed extract was $0.37 \%, 0.05 \%$ and $0.15 \%$, respectively (Wongcharee, Meeyoo, \& Chavadej, 2007). This present research is a comparative study on different materials used as a counter electrode to fabricate dye-sensitized solar cell (DSSC). These counter electrodes are coated with a conductive layer mostly of carbon. It has a key role as it catalyzes the reduction of the redox species in DSSCs. It helps external circuit to transfer electrons to triiodide and iodine in the redox (Zhang et al., 2011). Therefore, for considering a high performance DSSC, it requires to have a counter electrode material which is expected to have a good electrical and catalytic property with a chemically stable material (Kumar et al., 2015). Normally, Platinum (Pt) film is used widely as a catalyst in DSSC. But there are some issues with Pt which includes its high cost and availability. So to fabricate dye-sensitized solar cells (DSSCs), it is the main focus to use a material with low cost, easy availability and most importantly with high conductivity (Maiaugree et al., 2015). The aim of this research is to test and made comparative study by substituting the 'Pt' with Graphene, Graphene Dioxide and Poly-analine. For considering these materials, objective was their cost and electrical conductivity which effective the power conversion efficiency of the dye sensitized solar cell.

\section{Experiment}

Two steps procedure was adopted for fabrication of DSSC. Firstly, graphene, graphene oxide and poly-aniline were prepared for coating of counter electrode. In the second phase of experiment dye sensitized solar cell was fabricated by using these coated counter electrodes.

\subsection{Synthesis of Conduction Polymers for counter electrode}

Following are materials which were synthesis for the fabrication of counter electrode:

\subsubsection{Graphene and Graphene Oxide}

Graphene was prepared by the reduction of above prepared graphene oxide. For the synthesis of graphene, $350 \mathrm{mg}$ of already prepared graphene oxide was dispersed in $350 \mathrm{~mL}$ of distilled water and then $5 \mathrm{~mL}$ of $80 \%$ hydrazine hydrate was added. The solution was heated at $100{ }^{\circ} \mathrm{C}$ for $4 \mathrm{~h}$ until solution transferred into black suspension from yellow brown (Hu et al., 2011). Subsequently, this solution was cooled, filtered and washed with ethanol and water several times and dried in oven at $50{ }^{\circ} \mathrm{C}$ till complete drying.

Graphene oxide was prepared by oxidation of pure graphite powder. $3 \mathrm{~g}$ of graphite powder and $3 \mathrm{~g}$ of sodium nitrate was taken in $150 \mathrm{~mL}$ of concentrated sulphuric acid in a beaker in ice bath. Afterwards, $9 \mathrm{~g}$ of potassium permanganate was added in it gradually. This solution 
was then shifted to $40{ }^{\circ} \mathrm{C}$ temperature hot plate and stirred for $2 \mathrm{~h}$. Then $150 \mathrm{~mL}$ of distilled water was slowly added slowly which raised the temperature of solution up to $98{ }^{\circ} \mathrm{C} .30 \mathrm{ml}$ of $80 \%$ hydrogen oxide was added in it and stirred for further $10 \mathrm{~min}$ and then diluted with 700 $\mathrm{mL}$ of distilled water. This solution was filtered and washed with distilled water until $\mathrm{pH}$ of solution became 7. Finally, it was dried at room temperature to get graphene oxide in powder form (Hu et al., 2011).

\subsubsection{Poly-analine}

$5 \mathrm{~mL}$ aniline was dispersed in $90 \mathrm{~mL}$ of $1 \mathrm{M}$ hydrochloric acid in ice bath. Meanwhile $2.5 \mathrm{~g}$ of potassium dichromate was dissolved in $100 \mathrm{~mL}$ of $1 \mathrm{M}$ hydrochloric acid and placed in refrigerator. This pre-cooled solution was then added dropwise in aniline solution. After few minutes, this solution turned green which was the indication of polymerization. This solution was stirred for $4 \mathrm{~h}$ in ice bath and then left overnight to complete the polymerization at same temperature. After $24 \mathrm{~h}$ this solution was filtered and washed with water and then ethanol and dried in oven at $50{ }^{\circ} \mathrm{C}$. The dried polyaniline was then ground with pestle and mortar to get fine powder (Gull et al., 2016).

\subsection{Fabrication of DSSC}

\subsubsection{Development of semi-conductor}

For the fabrication of DSSC, ITOs were used but to develop a photoanode, a nano-crystalline semiconductor was developed. A paste of high viscosity of $\mathrm{TiO} 2$ was prepared to deposit on the ITO substrate. This paste was prepared in ethylene glycol. Before sintering, all the particles and fluids were blended so that mixture stabilizes both mechanically and chemically. 2 gram nano-powder of semiconductor was mixed with $100 \mathrm{ml}$ of ethylene glycol and stirred for 30 mins. As a result, highly viscous paste with a semiconductor metal oxide nanopowders was prepared. This paste can be deposited either by 'screen printing' or 'doctor's blade' method. In this experiment 'doctor's blade' method was used as shown in figure 1 .

Figure 1: Deposition of TiO2 paste

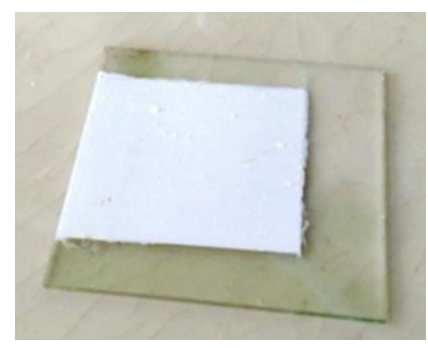
on Photo-anode (ITO Substrate)

\subsubsection{Preparation of Photocathode (Counter Electrode)}

Electrophoretic Deposition (EPD) technique is used for coating counter electrode (Choi et al., 2011; Jeon, Choi, Hwang, \& Kim, 2013).

This coating method comprises of two steps: 
- Preparation of suspension

- $\quad$ Electrophoretic Deposition (EPD)

\subsubsection{Preparation of Suspension}

A solution of $250 \mathrm{ml}$ of ethanol and $35 \mathrm{mg}$ of magnesium nitrate was taken in a beaker. $025 \%$ by weight of the materials (i.e. graphene, graphene dioxide and polyaniline) was taken into this solution. This mixture was taken for an ultrasonic bath for $1-2 \mathrm{~h}$. After the bath, mixture was ready for the electrophoretic deposition (EPD). Prepared suspension is shown in figure in 2 .

Figure 2: Suspension after sonication

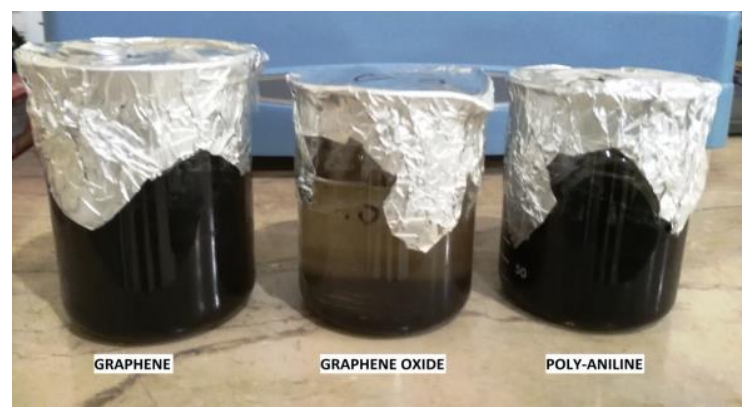

of three materials prepared

\subsubsection{Electrophoretic Deposition}

A dense black suspension was ready for EPD. ITO glass substrate was mounted as cathode of the circuit while a stainless steel substrate was used as anode for whole EPD setup. After that a DC voltage was applied for a specific time of $5 \mathrm{sec}$. According to a study the best result especially in case of graphene was deduce at 30 Volts for 5 - 10 seconds (Choi et al., 2011). So for this study same criteria were observed for applying voltages for the 10 seconds. After deposition, the substrate was annealed at $300^{\circ} \mathrm{C}$ for $1-2$ minutes as shown in figure 3 .

Figure 3: Deposition electrodes after EPD

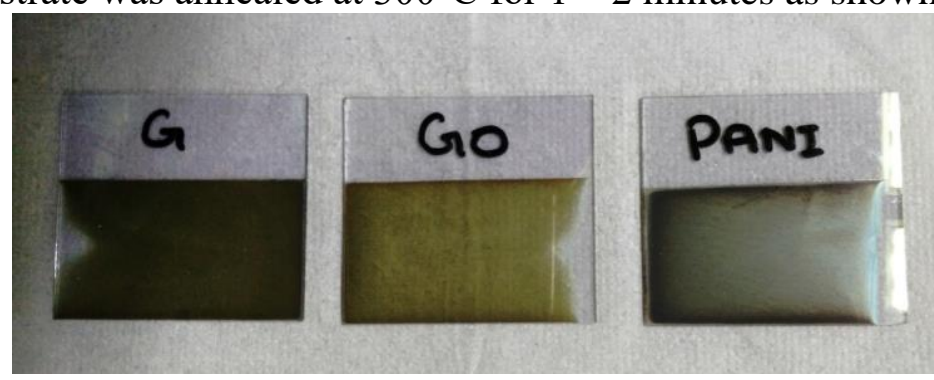

of layer on counter 


\subsubsection{Assembling of DSSC}

In this study N3 (cis-Bis(isothiocyanato) bis(2,2'-bipyridyl-4,4'-dicarboxylato ruthenium(II)) was used. This dye was prepared in $50 \mathrm{ml}$ of ethanol with 0.1 gram of N3 dye (powder). This mixture was put in ultrasonic bath for 45 minutes. After sonication, this mixture was stirred for $1 \mathrm{hr}$ at $50^{\circ} \mathrm{C}$. DSSC was prepared by sandwiching a photoanode and photocathode (Counter Electrode). Before the cell is sandwiched, coated photoanode with $\mathrm{TiO} 2$ was put in dye mixture so that $\mathrm{TiO} 2$ film may absorb dye for the photo catalytic process. This photoanode was left in N3 dye solution for two days under dark environment for better results. After the dye absorption, both photoanode and cathode were sandwiched to gather and tied up with the help of paper clip binder as shown in figure 4. Then two drops of electrolyte (Lithium Chloride Iodide/triiodide ions) were plunged on to the end joints of two substrates. Substrates were homogenized by shaking so that the entire electrolyte may spread between the whole cell. This electrolyte acts as a redox coupler and helps in transferring electron between anode and cathode of the DSSC. In this way a lab scale small DSSC becomes ready to test all the electrical properties of the cell.

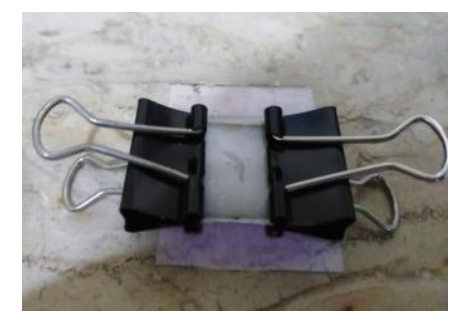

\section{Results}

\subsection{Optical Microscopy}

Initial investigation was made to check the uniformity and the nano-structure of the $\mathrm{TiO} 2$ which proved the nano particles of the TiO2 layer deposited on the ITO substrate. The image in figure 5 also confirmed a smooth and a fine layer of $\mathrm{TiO} 2$ paste firmly deposited on the substrate to form a perfect photo-anode for the fabrication of dye sensitized solar cell 
Figure 5: Optical Microscopy Images of $\mathrm{TiO}_{2}$ layer on ITO

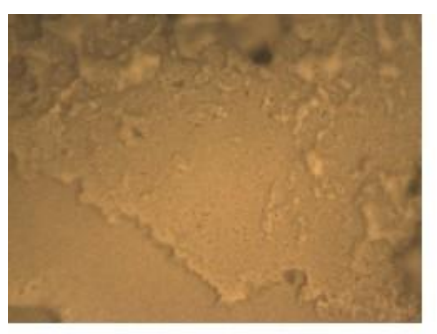

Optical Microscopy Image of $\mathrm{TiO}_{2}$ layer at $\mathrm{x} 5$ magnification level

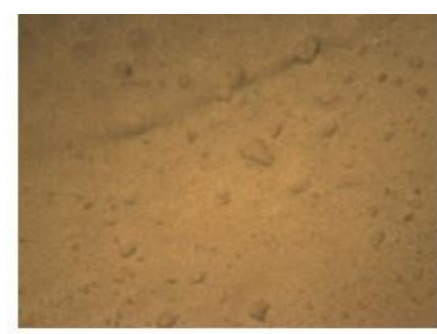

Optical Microscopy Image of $\mathrm{TiO}_{2}$ layer at x10 magnification level

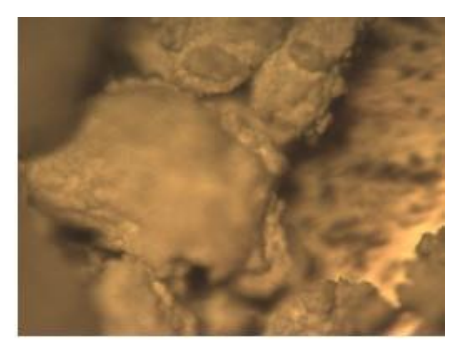

Optical Microscopy Image of $\mathrm{TiO}_{2}$ layer at x20 magnification level

\subsection{Scanning Electron Microscopy}

Counter electrodes fabricated by using Graphene, Graphene-Oxide and Poly-analine were investigated by scanning electron microscopy (SEM). Investigations related to the uniformity of the deposition and the morphology of the structure of materials used was carried out. From the SEM images in figure 6, it is clear that a thin layer of each material was deposit almost with $75 \%$ of uniformity. Some of the flakes were deposited in clusters which reduce the catalytic activity.

The other half of the figure 6 shows the structure of the particles of the materials. Graphene oxide flakes have a smooth and even surface while the Graphene consists of randomly aggregated crumpled particles which are due to the process of formation of graphene from graphene-oxide. While the third material, poly-analine has a typical worm like structure in cluster form. 
Figure 6: SEM images of counter electrode prepared by different materials

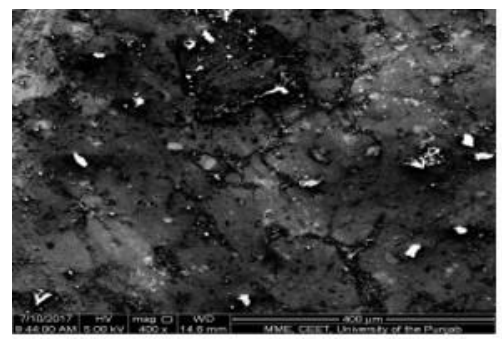

SEM image of Graphene deposited layer on ITOs

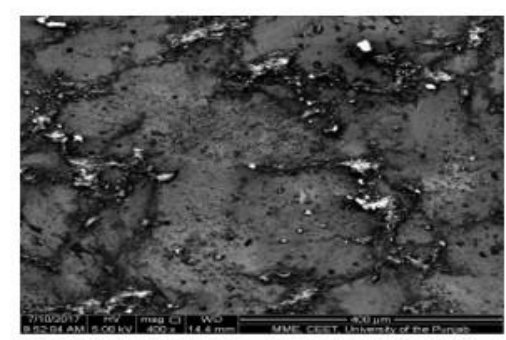

SEM Image of Grapheneoxide deposited layer on ITOs

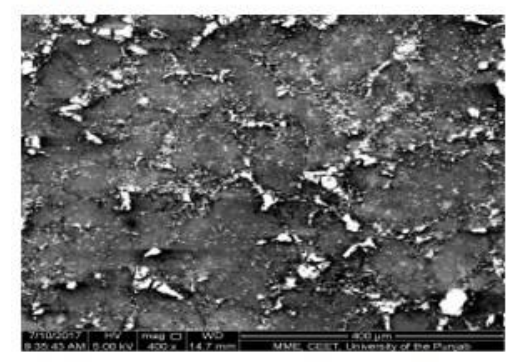

SEM Image of Poly-analine deposited layer on ITOs

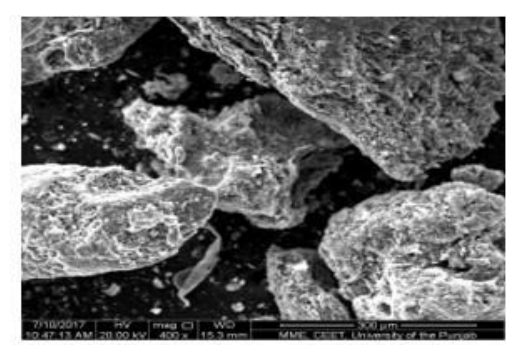

SEM image of Graphene flakes

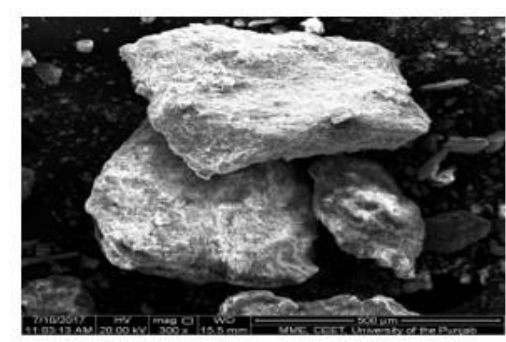

SEM Image of Grapheneoxide flakes

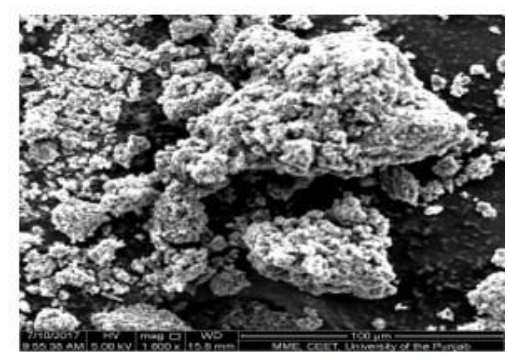

SEM Image of Poly-analine flakes

\subsection{Electrochemical Impedance Spectroscopy}

Electrostatic impedance spectroscopy (EIS) is considered as one of the least destructive and most informative techniques of electrochemical analysis available for determining the catalytic activities of counter electrode. A dummy cell with three electrodes was formed for EIS, where "Pt" was used as counter electrode, $\mathrm{Ag} / \mathrm{AgCl}$ as reference electrode while the third one was the deposited material on ITO which was under test. Same electrolyte (Lithium Chloride Iodide/triiodide ions) was used in this test which was previously used in DSSC fabrication.

Figure 7 shows graph which can be used to determine the catalytic activity of counter electrode. The region of semicircle within high frequency corresponds to charge transfer process between electrode and electrolyte, while the other one which is in the lower frequency 
range represent impedance of electrolyte. Equivalent circuit of the test cell prepared for performing EIS is also shown in figure 7.

Figure 7: Nyquist plot of Graphene, Graphene-oxide and Poly-analine counter electrode

\subsection{I-V Characteristics}

Photocurrent-voltage curves were formed to evaluate the overall efficiencies of the newly fabricated DSSCs by using three materials under observation. Parameters like open circuit voltage, Short circuit current, fill factor and efficiencies of each counter electrode were deduce from figure 8 and were summarized below in table 1 .

As the lower fill factor of the material exhibit to an inefficient link between electrolyte and the catalyst layer result in poor electronic efficiency, so from the figure 8 , it can be observed clearly that fill factor of graphene is least from all the three while poly-analine has the maximum fill factor between the three materials so it has a lower efficiency from all the three materials while polymaximum.

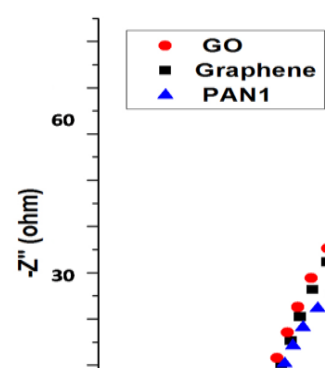

Figure 8: I-V Curves of DSSC with different counter electrode

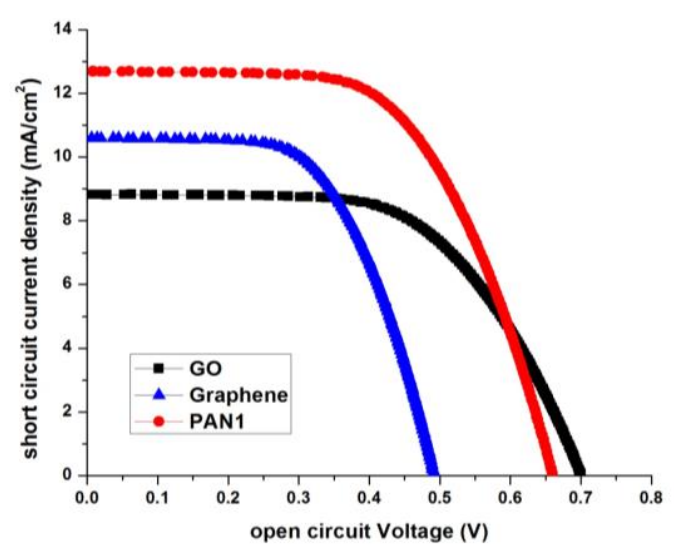
analine has the

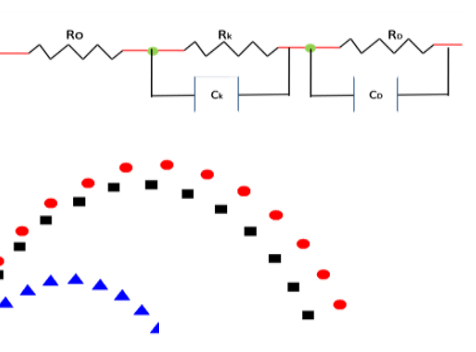

Table 1: Photovoltaic parameters of assembled DSSCs with different counter electrodes

\begin{tabular}{|c|c|c|c|c|}
\hline $\begin{array}{c}\text { IC. } \\
z^{\prime}(\mathrm{ohm})\end{array}$ & $\ldots$ & & & \\
\hline $\begin{array}{l}\text { Mate } \\
\text { rial }\end{array}$ & $\begin{array}{l}\mathbf{V} \\
\text { oc } \\
\text { (V) }\end{array}$ & $\begin{array}{c}\mathbf{J}_{\mathrm{SC}} \\
\left(\mathbf{m A} / \mathbf{c m}^{2}\right)\end{array}$ & $\begin{array}{c}\quad \text { Fil } \\
\text { Factor } \\
\text { (FF) }\end{array}$ & $\begin{array}{r}\text { Effici } \\
\text { ency }(\eta)\end{array}$ \\
\hline $\begin{array}{l}\text { Grap } \\
\text { hene }\end{array}$ & $492^{0 .}$ & 10.6 & $41^{0 .}$ & 2.10 \\
\hline $\begin{array}{l}\quad \text { Grap } \\
\text { hene } \\
\text { Oxide }\end{array}$ & $701{ }^{0 .}$ & 8.83 & $44^{0 .}$ & 2.90 \\
\hline $\begin{array}{l}\text { Poly- } \\
\text { Analine }\end{array}$ & $606^{0 .}$ & 12.7 & $50^{0 .}$ & 3.96 \\
\hline
\end{tabular}




\section{Conclusion}

Different tests were applied for concluding a comparative study between three different counter electrodes that were made in laboratory. After successful electrochemical impedance spectroscopy and photocurrent density-voltage curves a summarized result was made in figure 20. From the same figure it was concluded that graphene, graphene-oxide and poly-analine shows $0.492 \mathrm{~V}, 0.701 \mathrm{~V}, 0.606 \mathrm{~V}$ open circuit voltage respectively. Although Graphene-Oxide shows more open circuit voltage i.e. $0.701 \mathrm{~V}$ from poly-analine i.e. $0.606 \mathrm{~V}$ but due to poor fill factor and low short circuit current, it has lower efficiency than poly-analine. After calculating efficiency of all three counter electrodes it was concluded that poly-anailine shows maximum efficiency with $3.96 \%$ subsequently graphene-oxide $2.90 \%$ and graphene $2.10 \%$. Moreover, it is assumed that these materials exhibit high thermal and physical properties which may increase their potential for precise applications. Further studies are required to explore and enhance their potential for large scale activities.

\section{References}

Ahmad, M. S., Pandey, A., \& Rahim, N. A. (2017). Advancements in the development of $\mathrm{TiO} 2$ photoanodes and its fabrication methods for dye sensitized solar cell (DSSC) applications. A review. Renewable and Sustainable Energy Reviews, 77, 89-108.

Aleklett, K., \& Campbell, C. J. (2003). The peak and decline of world oil and gas production. Minerals and Energy-Raw Materials Report, 18(1), 5-20.

Chen, C., Chang, Y., \& Zhang, J. (2012). A SWNTs thin film solar microcell prepared by simple solution-evaporation method. Paper presented at the 2012 7th IEEE International Conference on Nano/Micro Engineered and Molecular Systems (NEMS).

Choi, H., Hwang, S., Bae, H., Kim, S., Kim, H., \& Jeon, M. (2011). Electrophoretic graphene for transparent counter electrodes in dye-sensitised solar cells. Electronics letters, 47(4), 281-283.

Gull, N., Khan, S. M., Islam, A., Zia, S., Shafiq, M., Sabir, A., . . Jamil, T. (2016). Effect of different oxidants on polyaniline/single walled carbon nanotubes composites synthesized via ultrasonically initiated in-situ chemical polymerization. Materials Chemistry and Physics, 172, 39-46.

Hara, K., Dan-oh, Y., Kasada, C., Ohga, Y., Shinpo, A., Suga, S., . . Arakawa, H. (2004). Effect of additives on the photovoltaic performance of coumarin-dye-sensitized nanocrystalline $\mathrm{TiO} 2$ solar cells. Langmuir, 20(10), 4205-4210.

Hu, H., Wang, X., Wang, J., Liu, F., Zhang, M., \& Xu, C. (2011). Microwave-assisted covalent modification of graphene nanosheets with chitosan and its electrorheological characteristics. Applied Surface Science, 257(7), 2637-2642.

Jeon, M.-H., Choi, H.-K., Hwang, S.-H., \& Kim, H.-k. (2013). Method for producing counter electrode based on electrophoretic deposition of graphene, counter electrode produced by the method and dye-sensitized solar cell including the counter electrode: Google Patents. 
Kumar, R., More, V., Mohanty, S. P., Nemala, S. S., Mallick, S., \& Bhargava, P. (2015). A simple route to making counter electrode for dye sensitized solar cells (DSSCs) using sucrose as carbon precursor. Journal of colloid and interface science, 459, 146-150.

Maiaugree, W., Lowpa, S., Towannang, M., Rutphonsan, P., Tangtrakarn, A., Pimanpang, S., . . J Jarernboon, W. (2015). A dye sensitized solar cell using natural counter electrode and natural dye derived from mangosteen peel waste. Scientific reports, 5, 15230.

Malik, A. S., Butt, O. M., Saad, M., \& Noor, Z. (2017). OVERVIEW AND PERFORMANCE ENHANCEMENT OF UNABRIDGED THIN FILM SOLAR CELL. JOURNAL OF FACULTY OF ENGINEERING \& TECHNOLOGY, 24(1), XX$\mathrm{XX}$.

Nazeeruddin, M. K., Kay, A., Rodicio, I., Humphry-Baker, R., Müller, E., Liska, P., . . . Grätzel, M. (1993). Conversion of light to electricity by cis-X2bis (2, 2'-bipyridyl-4, 4'-dicarboxylate) ruthenium (II) charge-transfer sensitizers (X= Cl-, Br-, I-, $\mathrm{CN}-$, and $\mathrm{SCN}-$ ) on nanocrystalline titanium dioxide electrodes. Journal of the American Chemical Society, 115(14), 6382-6390.

O'regan, B., \& Grfitzeli, M. (1991). A low-cost, high-efficiency solar cell based on dyesensitized. nature, 353(6346), 737-740.

Selim, Y., \& Mohamed, A. (2017). Role of dyestuff in improving dye-sensitized solar cell performance. Renewable Energy and Sustainable Development, 3(1), 79-82.

Wongcharee, K., Meeyoo, V., \& Chavadej, S. (2007). Dye-sensitized solar cell using natural dyes extracted from rosella and blue pea flowers. Solar Energy Materials and Solar Cells, 91(7), 566-571.

Zhang, D., Li, X., Li, H., Chen, S., Sun, Z., Yin, X., \& Huang, S. (2011). Graphene-based counter electrode for dye-sensitized solar cells. Carbon, 49(15), 5382-5388. 